\title{
КОРОНАВИРУС И УГОЛОВНОЕ ПРАВО, НЕОБХОДИМОСТЬ ИХ ОБЩЕГО АНАЛИЗА
}

\section{CORONAVIRUS AND CRIMINAL LAW, THE NEED FOR THEIR GENERAL ANALYSIS}

\section{E. Ilikbaeva}

Summary. The current situation with the new COVID-19 disease faced by modern humanity is unprecedented. This has brought many changes in various spheres of life. First, this concerns the development of medicine, chemistry, information technology, management, and organization of social processes. However, the sharp spread of the disease gave impetus to the legal regulation of public relations. Criminal law is no exception. The article analyzes the shortcomings and gaps of the criminal law caused by the pandemic. The latter is considered as a source of danger for the objects of criminal law protection. The most common cases of causing harm to objects of criminal law protection are analyzed. The article identifies the shortcomings of the legal regulation of criminal law relations in the context of the COVID-19 pandemic, as well as to develop proposals for their elimination.

Keywords: pandemic, coronavirus, COVID-19, criminal law, criminal law relations in a pandemic, punishments in a pandemic, national security, public relations.
$\Pi$ режде чем перейти к анализу правовых проблем, отметим, что пандемия может иметь уголовно-правовое значение лишь косвенно, как явление, представляющее общественную опасность.

Коронавирус и связанные с ним политические, социально-экономические, правовые и иные проблемы, возникшие именно из-за пандемии, ставят сложные задания практически перед всеми государствами, в том числе и перед Российской Федерацией.

Коронавирус сегодня стал мировой проблемой. Количество людей, которые заболели указанной болезнью на сегодняшний момент, составляет 249615518 человек, около 5049260 человек умерло [1]. Организации разного профиля как на международном уровне, так и на уровне государства предпринимают усилия разрешительно-стимулирующего и охранно-запрещающего характера для предотвращения и минимизации последствий пандемии.

\author{
Иликбаева Евгения Сергеевна \\ К.ю.н., Крымский филиал Краснодарского \\ университета МВД России, г. Симферополь \\ dilaila-77@yandex.ru
}

Аннотация. Нынешняя ситуация с новым заболеванием COVID-19, с которым столкнулось современное человечество, беспрецедентна. Это принесло большое количество изменений в различные сферы жизни. В первую очередь это касается развития медицины, химии, информационных технологий, управления и организации социальных процессов. Однако резкое распространение болезни дало толчок правовому регулированию общественных отношений. Уголовное законодательство не является исключением. В статье анализируются недостатки и пробелы части уголовного права вызванный пандемией. Последнее рассматривается как источник опасности для объектов уголовно-правовой охраны. Проанализированы наиболее распространенные случаи причинения вреда объектам уголовно-правовой охраны. В статье выявляются недостатки правового регулирования уголовно-правовых отношений в условиях пандемии COVID-19, а также разработать предложения по их устранению.

Ключевые слова: пандемия, коронавирус, COVID-19, уголовное право, уголовно-правовые отношения в условиях пандемии, наказания в условиях пандемии, национальная безопасность, общественные отношения.

Право, как известно, предоставляет указанным мерам официальный нормативно-обязательный характер, что упорядочивает их проведение.

При этом необходимо подчеркнуть, что необходимость противодействия Covid-19 предоставляет таким мерам более открытый, абсолютно прагматичный и рациональный характер. Все так называемые «полумеры», виртуально-идеалистические намерения не пригодны для применения в таких условиях. Именно такой рационально-прагматический подход должен доминировать и при оценке права (законодательства) на уровне определения и реального использования его возможностей. Не время и не место наделять в таких условиях право какими-то качествами и приписывать ему возможности, которые, по большому счету ему не присущи.

Все это относится и к уголовному праву, на которое в данных условиях возлагаются основные полномочия 
относительно правовой регламентации проведения охранно-карательных способов применения мер уголовной ответственности к лицам, которые нарушают установленные государством ограничения.

Так, повод является совсем недобрым, но одновременно он дает необходимость реально оценить возможности уголовного права, связанные с пандемией. В указанном ракурсе анализ коронавируса и уголовного права является необходимым. При этом необходимо учитывать сложность данной проблемы и сфокусироваться на социальном взгляде на указанную проблему, которая, с одной стороны, имеет разные проявления, но она объективно заслуживает такого анализа.

Сегодня информация про указанную вирусную инфекцию, без превышений является доминирующей во всех сферах государства. Коронавирус, который уже сегодня вызвал уровень смертности в мире 6,85\% [2], в Российской Федерации на сегодняшний день умерло более 244 тыс. человек [3]. В полной мере данная пандемия встала в ряд самых страшных заболеваний в истории человечества.

Следует отметить, что рядом с организационно-медицинскими мерами, направленными в первую очередь на разработку необходимой вакцины, непосредственное и профилактическое лечение, осуществление иных необходимых организационно - профилактических шагов, есть еще ряд социально-организационных мер, направленных на выявление заболевших, обособление от здоровых людей, приостановление любых мероприятий, которые дополнительно нарушают или значительно усложняют проведения необходимых противоэпидемиологических мероприятий, в частности распространения неправдивых сведений: нарушения условий пребывания в организациях, которые проводят карантинные меры, например нарушение условий самоизоляции.

В таких условиях одними из объективно необходимых, наравне с мерами административного законодательства, становятся меры уголовно-правового характера. Причем довольно часто при установлении опасных нарушений предпочтение отдаются уголовному праву.

Если обратить внимание на организацию противовирусных мероприятий в Китае, которые дали возможность достаточно быстро на территории государства улучшить ситуацию, в том числе и в провинции Ухань. Одним из основных и наиболее действенных способов воздействия на сознание и поведение людей, которые нарушали установленные государством правила и ограничения, или для удержания их от таких нарушений стали предписания уголовного права. Правитель- ством Китая практически сразу было установлено наказание в виде лишения свободы на срок от 3 до 10 лет, пожизненное лишение свободы и смертная казнь за то, что человек, имея, например, явные симптомы заболевания (кашель, температура) не уведомит про это, или те, кто были в Ухани, общался с теми, кто посещал указанную провинцию и не обратился к медикам [4]. Более суровое наказание для лиц, которые нарушили правила самоизоляции, не носят маску посещая общественные места, что мы сейчас наблюдать повсеместно в России. Тяжесть наказания относительно конкретного человека избирается в зависимости от последствий, к которым привели действия нарушителя. Необходимо сказать, что такие преступления в Китае рассматриваются не как преступления против здоровья населения, а как преступления против общественной безопасности, считаем данная позиция правительства Китая показательна, ведь уровень правосознания граждан.

Например, в отличии от уголовного законодательства большинства стран, в том числе и от уголовного законодательства России, китайское уголовное право предусматривает только один вид мягкого наказания и только для юридических лиц - штраф, не предусматривая ни конфискации имущества, ни ликвидации такого юридического лица.

Что же касается стран Европы, то следует отметить, что, например, в небезопасных провинциях Италии Ломбардии и Болони размер штрафа до 5000 тыс. евро, или арест до 3-х месяцев [5]. Необходимо также обратить внимание на регламентацию в европейских странах наказания за распространение «фейковых» новостей относительно распространения коронавируса.

Каким бы демократичным и гуманным не были государства Европы в случае необходимости четкого решения конкретной проблемы, в попытке максимально придерживаться людьми установленных ограничений, правительство в указанных государствах реально демонстрирует, что усиление прямых принудительных мер воздействия на население, т.е. страх перед наказанием становится одним из основных, если вообще не основным способом выстраивания общественных отношений в государстве. Именно так используются возможности уголовного права.

Российская Федерация также имеет необходимый уголовно-правовой инструмент, а именно ст. 236 УК РФ, предусматривает уголовную ответственность за нарушение санитарно - эпидемиологических правил, в рассматриваемую статью на основании Федерального закона № 100 от 01.04.2020 года внесены изменения в первую очередь изменения связанные с усилением наказания, такая реакция законодателя была понятной и необходи- 
мой с одной стороны, но с другой стороны сделает отметить, что до внесения изменений в указанную статью, уголовная ответственность наступала за нарушение санитарно-эпидемиологических правил повлекшее по неосторожности массовое заболевание или отравление людей, т.е. состав до 01.04.2020 года был материальным, а после внесенных изменений «либо создавшее угрозу наступления таких последствий» законодатель счел необходимым отнести ч. 1 ст. 236 УК РФ к формальному составу (усеченному). Также довольно остро встает вопрос о разграничении ст. 236 УК РФ со смежным административным правонарушением (ст. 6.3. КоАП).

Содержание и направление такого усовершенствования не является обоснованным, и считаем, что необходимо более значительные подходы к пониманию уголовного права, которое должно запрещать определенные виды поведения (поступков), которые нарушают установленные государством запреты в таких условиях.

Существует также непрямая связь коронавируса и уголовного законодательства, а именно протекание указанного заболевания, применение определенных ограничительных мер, в том числе и карантинных, во всех этих формах могут быть не простые социально-психологические и иные проявления, что в свою очередь играет опосредованное отношение к уголовному праву.

Например, на фоне коронавирусной пандемии в ЮАР массовые беспорядки и мародерства. Стоит от- метить доклад Европола «Пандемический спекулянт: как преступники эксплуатируют кризис COVID-19» [6], в указанным докладе говорится о росте киберпреступности, мошенничестве, а также о новом типе организованной «карантинной» преступности.

На сегодняшний день опасный коронавирус выступает не только опасным вирусным заболеванием, но и является социально-негативной проблемой, которая угрожает всему мировому сообществу.

Подводя итого следует отметить, что противодействие этому медико-социальному явлению требует наравне с мероприятиями, которые уже проводятся, постоянной разработки и внедрения в общественную жизнь комплексных шагов. При этом сложность влияния на указанное явление, требует необходимости разработки реальных, а не декларативных мер. Это непосредственно касается и установления обязательных медико-социальных «табу» сущность которых заключается в прямом запрете совершения определенных действий разного характера, которые подрывают весь комплекс таких шагов. Именно эти события показывают, что уголовно-правовые предписания - это прямой запрет соответствующего поведения людей под страхом, в случае нарушения установленного запрета, наказания, причем такого которое имеет негативные последствия. Необходимо подчеркнуть, что установление уголовно-правовых запретов должно с самого начала предусматривать, что соответствующее деяние является общественно опасным для социального развития.

\section{ЛИТЕРАТУРА}

1. Коронавирус в Мире, свежая статистика на сегодня по заболевшим [Электронный ресурс] URL: https://coronavirus-graph.ru/mir

2. Россия продолжает обновлять антирекорды по смертности от Сovid-19 [Электронный ресурc] URL: https://eadaily.com/ru/news/2021/11/20/rossiyaprodolzhaet-obnovlyat-antirekordy-po-smertnosti-ot-covid-19

3. В России обновлен антирекорд суточной COVID-смертности [Электронный ресурс] URL: https://стопкоронавирус.pф/news/20200508-1630.html\#: : text=B\%20Роспотребнадзоре\%20назвали\%20уровень\%20смертности, обращения»\%2C\%20—\%20цитирует\%20Попову\%20ТACC

4. В Китае перечислили связанные с коронавирусом нарушения, за которые грозит смертная казнь [Электронный pecypc] URL: https://www.newsru.com/ world/15feb2020/death_china.html

5. Italy imposes region-wide coronavirus quarantine in Lombardy [Электронный ресурc] URL: https://www.dw.com/en/italy-imposes-region-wide-coronavirusquarantine-in-lombardy/a-52679158

6. Спекуляция пандемией, как преступники используют кризис COVID-19. Март 2020 г. [Электронный ресурc] URL: https://mвд.pф/upload/site1/folder_ page/019/882/802/Evropol_Spekulyatsiya_pandemiey1.pdf

(с) Иликбаева Евгения Сергеевна ( dilaila-77@yandex.ru ).

Журнал «Современная наука: актуальные проблемы теории и практики» 